\title{
Weight-length relationship, morphometric and meristic characters of the yellow seahorse Hippocampus kuda Bleeker, 1852 (Syngnathiformes: Syngnathidae) from central west coast of India
}

\author{
H. B. PAWAR, S. V. SANAYE, R. A. SREEPADA AND B. S. INGOLE \\ Aquaculture Laboratory, Biological Oceanography Division, CSIR-National Institute of Oceanography, Dona Paula \\ Goa - 403 004, India \\ e-mail: sreepada@nio.org; sreepada63@gmail.com
}

\begin{abstract}
Eighteen morphometric and five meristic characters of the yellow seahorse Hippocampus kuda Bleeker, 1852 inhabiting the coastal waters of Ratnagiri, central west coast of India, were studied. Morphometric/numerical analysis confirmed the identity of the species from Ratnagiri coastal waters as Hippocampus Kuda Bleeker, 1852. A negative allometric relationship was observed in both genders of $H$. kuda. The estimated weight-length relationships (WLR) for male and female specimens, respectively were, $\mathrm{W}=0.0034 \mathrm{SL}^{2.8533}$ and $\mathrm{W}=0.0078 \mathrm{SL}^{2.5253}\left(\mathrm{r}^{2}>0.95\right)$. The biological information on morphometric and meristic characters, WLR and length-length relationship (LLR) provided in this study would be helpful for conservation and management of this vulnerable seahorse species.
\end{abstract}

Keywords: Hippocampus kuda, Length-length relationship, Meristic, Morphometric, Weight-length relationship, Yellow seahorse

Seahorses, pipefishes, pipehorses and seadragons are members of the family Syngnathidae (Syngnathiformes), which include 320 species under 56 genera (Kuiter, 2009). Seahorses, representing the subfamily Hippocampinae, under the genus Hippocampus are characterised by a fully enclosed brood pouch with a small opening for the transfer of eggs, vestigial caudal fin and a prehensile tail (Lourie et al., 1999; Lourie et al., 2004). Till date, 41 valid species of seahorses are reported around the world (Lourie et al., 2016). The yellow seahorse Hippocampus kuda Bleeker, 1852 is considered as one of the most complex seahorse species with respect to taxonomy, because the name $H$. kuda, was in use earlier for all non-spiny seahorses in the Indo-Pacific region (Lourie et al., 1999). Distinct morphometric features of $H$. $k u d a$ are: single eye and cheek spine, rounded and backward curled coronet; deeper head and rounded or less developed body spines (Lourie et al., 1999; 2004). An exhaustive taxonomic work by Lourie et al. (1999) suggested that at least 15 names of apparent species are merely synonyms of H. kuda. Species such as Barbour's seahorse H. barbouri, the Reunion seahorse $H$. borboniensis, the tiger tail seahorse H. comes, Fisher's seahorse H. fisheri, the sea pony $H$. fuscus and the great seahorse H. kelloggi, which were included under $H$. kuda species complex, have later been isolated as separate species (Lourie et al., 1999). Howerver, based on recent extensive morphometric and molecular studies by Lourie etal. (2016), it has now been confirmed that $H$. borboniensis and $H$. fuscus are also synonyms of
$H$. kuda due to lack of distinguishable morphological, genetic and/or geographic differences from $H$. kuda. The escalating trade and worldwide decline in seahorse populations reiterate the need to resolve seahorse taxonomy (Bijukumar et al., 2008). Precise species identification will help to modify fishing practices appropriately to conserve seahorse populations, design protective marine reserves, assess captive breeding potential for seahorses and develop protective legislations (Sreepada et al., 2002; Bijukumar et al., 2008; CITES, 2018).

Weight-length relationship (WLR) has been widely employed in fisheries research because it allows the conversion of growth-in-length equations to growth-inweight, stock assessment models (Pauly, 1993; Petrakis and Stergiou, 1995) as well as in estimation of biomass from length observations. Furthermore, often WLRs are useful in estimating the condition indices and life history stages, thus allowing morphological comparison of populations from different regions (LeCren, 1951; Petrakis and Stergiou, 1995). Relationships between different types of lengths (length-length relationships, LLR), are also important for comparative growth studies (Kara and Bayhan, 2008). Unfortunately, such information is scanty for $H$. kuda, which is one of the highly valued seahorse species popularly traded for both, traditional Chinese medicine (TCM) and aquaria (Vincent, 1996). Moreover, H. kuda has been listed as 'vulnerable' in 
the IUCN Red List of Threatened Species (Aylesworth, 2014). Also, seahorses are first amongst the marine fishes of commercial importance listed in CITES with regard to regulation of its international trade (CITES, 2018).

Based on molecular studies, Teske et al. (2005) found that $H$. kuda population inhabiting east and west coasts of India are genetically distinct and H. kuda population from India were the oldest one. Therefore, the present study was undertaken to update the knowledge on morphological features which could be useful for comparing Indian populations of $H$. kuda with that from the rest of the world. Dead specimens of $H$. kuda landed as incidental catches in gillnets (mesh size 2.5 to $4.0 \mathrm{~cm}$ ) operated by local fishermen in the Mirya Creek, Ratnagiri $\left(17^{\circ} 02^{\prime} 52^{\prime \prime} \mathrm{N} ; 73^{\circ} 16^{\prime} 08^{\prime \prime} \mathrm{E}\right)$ at water depths of 2-10 $\mathrm{m}$, formed the study material. The habitat and bottom topography mostly comprises oyster beds with small rock pebbles, rocky bottom with brown seaweed, Sargassum sp. and sandy bottom. Fishes were sexed based on the presence or absence of a brood pouch and morphometric measurements as well as meristic characters were taken on wet seahorses ( 60 male and 58 females) at the landing site. Morphometric characters such as height $(\mathrm{Ht})$, standard length (SL), head length (HL), trunk length (TrL), tail length (TaL), snout length (SnL), snout depth (SnD), head depth (HD), spine width (SW), pectoral fin base length (PL) and dorsal fin base length (DL) were taken with the help of a caliper with $0.1 \mathrm{~mm}$ precision (Lourie et al., 1999; Lourie, 2003; Lourie et al., 2004). Coronet height $(\mathrm{CH})$ was measured as vertical distance between tip of the coronet and first spine of cleithral ring. Trunk depth on $4^{\text {th }}$ trunk ring (TD4) was recorded as narrowest distance between the superior and inferior trunk ridges on $4^{\text {th }}$ trunk ring whereas, trunk depth on $9^{\text {th }}$ trunk ring (TD9) were recorded as narrowest distance between the superior and inferior trunk ridges on $9^{\text {th }}$ trunk ring. Meristic counts included the number of trunk rings (TrR), tail rings (TaR), dorsal fin rays (DF), pectoral fin rays (PF) and anal fin rays (AF) which were counted as described by Lourie et al. (1999). For WLR studies, weight measurements of wet individuals were also taken.

Mann-Whitney $U$ test (Siegel, 1956) was used to test significant difference between meristic counts of male and female specimens. The WLRs in H. kuda was established for males and females, using the formula $\mathrm{W}=a \mathrm{SL}^{b}$ and linear regression analysis, $\log \mathrm{W}=a+b \log \mathrm{SL}$, where ' $a$ ' is the intercept of the regression curve and ' $b$ ' is the regression coefficient (slope). The degree of association between the variables was computed by the determination coefficient, $r^{2}$. A Student $t$-test was applied to determine whether the regression coefficients $(b)$ obtained from the linear regression differed significantly from the isomeric value of 3. Significant difference was tested at a $5 \%$ level, represented as $\mathrm{p}<0.05$.

The entire body colour of freshly landed wet specimens was observed to be bright yellow, orange with small reddish spots and brownish black. The shape of the coronet was observed to be round, medium size and overhanging towards the back with a cup like depression on top. In freshly landed fishes, prominent round bumps with white patch were observed on 1-, 4-, 7- and 11- TrR, whereas bumps and patches were observed on 5-, 9-, 13-, 17-, 20-, 23-, 26-, 29-, 32- and 34- or 35- TaR on the dorsal side. Dorsal fin originated between $9^{\text {th }}$ and $10^{\text {th }} \operatorname{TrR}$ and terminated between $1^{\text {st }}$ and $2^{\text {nd }} \mathrm{TaR}$.

The minimum, maximum and mean values of measured morphometric characters $( \pm \mathrm{SD})$ of male and female specimens of $H$. kuda collected from Ratnagiri are presented in Table 1. No gender-wise significant difference in measured morphometric characters (SL, Ht, TrL, PFH, DFH, AFH, PL, DL, AL, TD4, TD9 and SW) was discernible $(\mathrm{p}>0.05)$.

Significant differences $(p<0.05)$ were observed gender-wise in morphometric characters such as HL, HD, $\mathrm{SnD}, \mathrm{SnL}$, TaL and $\mathrm{CH}$. Meristic counts recorded are presented in Table 2. The number of TrR was 11 in both male and female $H$. kuda, whereas, in males the median number of TaR was 35 (32-37), while in females it was 33 (33-36). Results of Mann-Whitney $U$ test showed that the number of TaR, PF and DF varied significantly between male and female $(p<0.05)$. Morphometric and meristic characters recorded in specimens of $H$. kuda collected from Ratnagiri coast were similar to those described earlier by Lourie et al. (1999; 2004), Choo and Liew (2004) and Thangaraj and Lipton (2011). Comparative assessment of the morphometric and meristic characters measured, with those described by Lourie et al. (1999), confirmed the taxonomic identity of seahorse species inhabiting coastal waters of Ratnagiri, as $H$. kuda. Due to obvious difficulties in differentiation, H. fuscus is often misidentified as H. kuda (Thangaraj and Lipton, 2011). But very recently, studies by Lourie et al. (2016) confirmed that $H$. fuscus is a synonym of $H$. kuda due to lack of prominent differences in morphological characters, geographical distribution and genetics between these two species. Maximum height of seahorse species is a quite useful parameter for taxonomical differentiation, as it allows elimination of some seahorse species. For example, a smaller-sized seahorse species like Japanese seahorse, H. mohnikei (max height, $8 \mathrm{~cm}$ ) cannot be a larger-sized seahorse species like $H$. kuda (max height, $17 \mathrm{~cm}$ ) (Lourie et al., 2004). The recorded maximum height of freshly caught male $(18.8 \mathrm{~cm})$ and female $(18.5 \mathrm{~cm})$ specimens of $H$. kuda in the present study were relatively higher 
Table 1. Morphometric characters of $H$. kuda inhabiting the coastal waters of Ratnagiri, central west coast of India

\begin{tabular}{|c|c|c|c|c|c|c|c|}
\hline \multirow{2}{*}{ Morphometric character } & \multicolumn{3}{|c|}{ Male $(n=60)$} & \multicolumn{3}{|c|}{ Female $(n=58)$} & \multirow{2}{*}{ Mean as $\%$ of SL } \\
\hline & Min & Max & Mean \pm SD & Min & Max & Mean \pm SD & \\
\hline Standard length & 12.90 & 20.50 & $17.18 \pm 1.89$ & 13.30 & 20.40 & $17.50 \pm 1.55$ & - \\
\hline Height & 12.10 & 18.80 & $15.63 \pm 1.64$ & 12.50 & 18.50 & $15.85 \pm 1.29$ & 90.77 \\
\hline Head length & 2.25 & 3.30 & $2.82 \pm 0.24^{*}$ & 2.60 & 3.20 & $2.97 \pm 0.13^{*}$ & 16.71 \\
\hline Snout length & 0.85 & 1.40 & $1.12 \pm 0.15^{*}$ & 1.00 & 1.40 & $1.24 \pm 0.08^{*}$ & 6.80 \\
\hline Snout depth & 0.30 & 0.50 & $0.41 \pm 0.05^{*}$ & 0.30 & 0.50 & $0.44 \pm 0.05^{*}$ & 2.44 \\
\hline Head depth & 1.25 & 1.80 & $1.46 \pm 0.12 *$ & 1.35 & 1.70 & $1.54 \pm 0.10^{*}$ & 8.67 \\
\hline Trunk length & 3.90 & 5.30 & $4.54 \pm 0.37$ & 4.20 & 5.40 & $4.98 \pm 0.36$ & 27.44 \\
\hline Tail length & 7.60 & 11.50 & $9.84 \pm 1.03^{*}$ & 7.60 & 10.90 & $9.59 \pm 0.91 *$ & 56.04 \\
\hline Coronet height & 0.70 & 1.10 & $0.85 \pm 0.07 *$ & 0.60 & 0.95 & $0.78 \pm 0.09 *$ & 4.69 \\
\hline Pectoral fin height & 0.35 & 0.65 & $0.53 \pm 0.07$ & 0.40 & 0.50 & $0.53 \pm 0.05$ & 3.04 \\
\hline Dorsal fin height & 0.45 & 0.70 & $0.56 \pm 0.06$ & 0.40 & 0.65 & $0.52 \pm 0.06$ & 3.11 \\
\hline Anal fin height & 0.50 & 0.80 & $0.42 \pm 0.05$ & 0.26 & 0.66 & $0.42 \pm 0.06$ & 2.48 \\
\hline Pectoral fin base length & 0.50 & 0.80 & $0.63 \pm 0.07$ & 0.45 & 0.80 & $0.61 \pm 0.08$ & 3.58 \\
\hline Dorsal fin base length & 1.15 & 1.70 & $1.48 \pm 0.15$ & 1.25 & 1.70 & $1.48 \pm 0.13$ & 8.52 \\
\hline Anal fin base length & 0.10 & 0.35 & $0.22 \pm 0.06$ & 0.26 & 0.66 & $0.46 \pm 0.4$ & 1.97 \\
\hline TD4 & 0.85 & 1.35 & $1.06 \pm 0.11$ & 0.80 & 1.40 & $1.10 \pm 0.13$ & 6.23 \\
\hline TD9 & 1.50 & 2.20 & $1.79 \pm 0.17$ & 1.30 & 2.05 & $1.79 \pm 0.18$ & 1.32 \\
\hline Spine width & 0.35 & 0.80 & $0.59 \pm 0.12$ & 0.45 & 0.95 & $0.63 \pm 0.10$ & 3.53 \\
\hline
\end{tabular}

*Indicate significant difference between two genders $(\mathrm{p}<0.05)$

Table 2. Meristic counts of male and female specimens of $H$. kuda collected from the coastal waters of Ratnagiri, central west coast of India

\begin{tabular}{|c|c|c|c|c|c|c|c|c|c|}
\hline \multirow{2}{*}{ Meristic character } & \multicolumn{4}{|c|}{ Male $(n=60)$} & \multicolumn{4}{|c|}{ Female $(n=58)$} & \multirow{2}{*}{$U$} \\
\hline & Min & Max & Mean & Median & Min & Max & Mean & Median & \\
\hline Trunk rings & 11 & 11 & 11 & 11 & 11 & 11 & 11.00 & 11 & $\mathrm{p}<0.05$ \\
\hline Tail rings & 32 & 37 & 35.03 & 35 & 33 & 36 & 33.74 & 33 & $\mathrm{p}>0.05$ \\
\hline Dorsal fin rays & 17 & 19 & 17.84 & 17 & 17 & 19 & 17.33 & 17 & $\mathrm{p}>0.05$ \\
\hline Pectoral fin rays & 16 & 17 & 16.35 & 16 & 15 & 17 & 16.14 & 16 & $\mathrm{p}>0.05$ \\
\hline Anal fin rays & 4 & 5 & 4.06 & 4 & 4 & 4 & 4 & 4 & $\mathrm{p}<0.05$ \\
\hline
\end{tabular}

than previously reported for the same species $(17 \mathrm{~cm})$ by Lourie et al. (2004). The higher maximum height recorded in male and female specimens of $H$. kuda in the study region compared to previous reports could be attributed to absence of commercial exploitation (target fishing and seahorse trade) and food availability.

Different types of length-length relationships (LLR) determined separately for the two genders and pooled data of H. kuda are presented in Table 3. All LLRs showed significant positive correlation between different length measurements. LLR of fish species under various environmental conditions will allow more reliable comparative assessment between populations (Kara and Bayhan, 2008). Furthermore, knowledge on LLR is of great importance for comparative growth studies (Moutopoulos and Stergiou, 2002). Considering the scanty information on LLR in syngnathid fishes, the LLR reported for $H$. kuda during the present study, might be of use for comparison of different populations of $H$. kuda from various geographical regions.

The estimated values of WLR parameters are presented in Table. 4. In the present study, the calculated ' $b$ ' values for males (2.8533) and females (2.5253) are indicative of negative allometric growth $(<3.0)$. A significant difference in $b$ values of male and female H. kuda $(\mathrm{p}<0.05)$ was also observed. The estimated WLR was, $\mathrm{W}=0.0034 \mathrm{SL}^{2.8533}$ for males and $\mathrm{W}=0.0078 \mathrm{SL}^{2.5253}$ for females.

A similar negative allometric growth pattern has been observed in laboratory reared $H$. kuda juveniles ( $b=2.76)$ by Choo and Liew (2006) and in wild caught males $(b=2.42)$ and females $(b=1.72)$ by Vaitheeswaran and Venkataramani (2012) from Thoothukudi, south-east coast of India. Negative allometric growth pattern has also been observed in a few other seahorse species as well 
Table 3. Length-length relationships (LLR) of $H$. kuda collected from the coastal waters of Ratnagiri, central west coast of India

\begin{tabular}{|c|c|c|c|c|c|c|}
\hline \multirow[t]{2}{*}{ LLR } & \multicolumn{2}{|c|}{ Male $(n=60)$} & \multicolumn{2}{|c|}{ Female $(n=58)$} & \multicolumn{2}{|c|}{ Pooled $(n=118)$} \\
\hline & $r$ & Regression equation & $r$ & Regression equation & $r$ & Regression equation \\
\hline Ht on SL & 0.9643 & $\mathrm{Ht}=1.2737+0.8358 \mathrm{SL}$ & 0.9816 & $\mathrm{Ht}=1.5869+0.8149 \mathrm{SL}$ & 0.9708 & $\mathrm{Ht}=1.4516+0.8261 \mathrm{SL}$ \\
\hline $\operatorname{TrL}$ on $\mathrm{SL}$ & 0.8666 & $\operatorname{TrL}=1.6649+0.1676 \mathrm{SL}$ & 0.8897 & $\operatorname{TrL}=1.2865+0.2109 \mathrm{SL}$ & 0.7908 & $\operatorname{TrL}=1.3738+0.1952 \mathrm{SL}$ \\
\hline TaL on SL & 0.9747 & $\mathrm{TL}=0.7426+0.5293 \mathrm{SL}$ & 0.9326 & $\mathrm{TL}=0.0909+0.05425 \mathrm{SL}$ & 0.9316 & $\mathrm{TL}=0.6535+0.5227 \mathrm{SL}$ \\
\hline SnL on HL & 0.9014 & $\mathrm{SnL}=0.3767+0.5283 \mathrm{HL}$ & 0.7363 & $\mathrm{SnL}=0.0446+0.4332 \mathrm{HL}$ & 0.8731 & $\mathrm{SnL}=-0.4183+0.5510 \mathrm{HL}$ \\
\hline HD on HL & 0.8798 & $\mathrm{HD}=0.2250+0.4386 \mathrm{HL}$ & 0.8290 & $\mathrm{HD}=-0.4039+0.6545 \mathrm{HL}$ & 0.8626 & $\mathrm{HD}=0.0778+0.4918 \mathrm{HL}$ \\
\hline SW on TD9 & 0.8142 & $\mathrm{SW}=-0.4080+0.5600 \mathrm{TD} 9$ & 0.8594 & $\mathrm{SW}=0.0699+0.3875 \mathrm{TD} 9$ & 0.8072 & $\mathrm{SW}=0.2427+0.4754 \mathrm{TD} 9$ \\
\hline TD4 on TrL & 0.7649 & $\mathrm{TD} 4=0.0308+0.2257 \mathrm{TrL}$ & 0.8187 & $\mathrm{TD} 4=-0.3112+0.2845 \mathrm{TrL}$ & 0.7689 & $\mathrm{TD} 4=0.0489+0.2168 \mathrm{TrL}$ \\
\hline TD9 on TrL & 0.8467 & TD9 $=-0.0695+0.4083 \operatorname{TrL}$ & 0.8891 & TD9 $=-0.3512+0.4304 \operatorname{TrL}$ & 0.7525 & $\mathrm{TD} 9=0.3065+0.3115 \operatorname{TrL}$ \\
\hline DL on $\operatorname{TrL}$ & 0.8293 & $\mathrm{DL}=0.0212+0.2930 \operatorname{TrL}$ & 0.7650 & $\mathrm{DL}=0.0599+0.3116 \operatorname{TrL}$ & 0.6869 & $\mathrm{DL}=0.4098+0.2245 \operatorname{TrL}$ \\
\hline PL on TrL & 0.8387 & $\mathrm{PL}=-0.3760+0.1974 \mathrm{TrL}$ & 0.7101 & $\mathrm{PL}=-0.0155+0.1428 \operatorname{TrL}$ & 0.6869 & $\mathrm{PL}=0.4098+0.2245 \mathrm{TrL}$ \\
\hline
\end{tabular}

Table 4. Weight-length relationship (WLR) of $H$. kuda collected from the coastal waters of Ratnagiri, central west coast of India

\begin{tabular}{|c|c|c|c|c|c|c|c|c|c|}
\hline \multirow{2}{*}{ Gender } & \multirow{2}{*}{$n$} & \multicolumn{2}{|c|}{ Standard length $(\mathrm{cm})$} & \multicolumn{2}{|c|}{ Weight (g) } & \multirow{2}{*}{$a$} & \multirow{2}{*}{$b$} & \multirow{2}{*}{ b 95\% C.I. } & \multirow{2}{*}{$r^{2}$} \\
\hline & & Min & Max & Min & Max & & & & \\
\hline Male & 60 & 12.9 & 20.50 & 5.0129 & 18.8993 & 0.0034 & 2.8533 & $2.6341-3.0739$ & 0.9605 \\
\hline Female & 58 & 13.3 & 20.40 & 5.6778 & 17.2145 & 0.0079 & 2.5253 & $2.3115-2.7398$ & 0.9542 \\
\hline
\end{tabular}

(Gurkan and Taskavak, 2007; Basusta et al., 2014; Vieira et al., 2014; Balasubramanian and Murugan, 2017).

Gurkan and Taskavak (2007) observed a ' $b$ ' value of 2.47 in the long snouted seahorse, $H$. guttulatus collected from Aegean Sea, Turkey. Vieira et al. (2014) observed negative allometric growth $(b=2.95)$ in the short snouted seahorse, H. hippocampus inhabiting Ria Formosa, SW Iberian coast. Similarly, Basusta et al. (2014) observed negative allometric growth pattern in $H$. hippocampus ( $b=2.41)$ and $H$. guttulatus $(b=2.84)$ inhabiting eastern Black Sea and Balasubramanian and Murugan (2017) observed negative allometric growth (males $b=2.7$; females $b=2.5$ ) in $H$. kelloggi off Coromandel Coast, south-east coast of India. Many authors have hypothesised that the WLR depends on abiotic (temperature, salinity), biotic and biological factors (season, food availability, habitats, gonad development, health) and anthropogenic activities (habitat alteration/destruction, pollution and fishing pressure) (Gurkan and Taskavak, 2007; Vieira et al., 2014; Balasubramanian and Murugan, 2017). However, absence of targeted fishing and seahorse trade and bottom trawling as well as ample availability of live prey organisms over the oyster and Sargassum beds (pers. observ.) at the collection sites do not support either of the above contentions. Therefore, the most plausible explanation for negative allometric growth observed in different seahorse species seems to be linked more to their body structure rather than to other abiotic, biotic and anthropogenic factors. Seahorses have distinct morphological differences from other bony fishes for e.g., they have a layer of skin stretched over a series of bony plates in lieu of scales (Ginsburg, 1937; Harris et al., 2007). Furthermore, they lack fleshy muscles inside their body and much of the muscle tissue are confined to the prehensile tail, dorsal fin muscle support and superior trunk region (Thomson, 1993; Hale, 1996). Presence of scales, muscles, heavy jaws and well developed fins (especially caudal fin) which contribute to much of the weight in other fin fishes (more towards isometric or positive allometric WLR) are completely lacking in seahorses. Hence, a significant difference in weight and length proportions in seahorses might explain the negative allometric growth.

In conclusion, a detailed analysis of morphometric and meristic characters presented here would be helpful in identification of $H$. kuda. WLR derived in the present study might be useful to estimate weight parameter when only length data is known. Future studies with larger samples size would provide greater insights into the population characters of $H$. kuda and will aid conservation and management of the species inhabiting the study region.

\section{Acknowledgements}

The authors are grateful to the Director, CSIRNational Institute of Oceanography (CSIR-NIO), Goa for facilities and encouragement. The study was funded by the Department of Biotechnology (BT/PR/8271/ AAQ/03/308/2006), Govt. of India. First author (HBP) is thankful to CSIR for granting fellowship. Contribution No. 6416 from the CSIR-NIO, Goa.. 


\section{References}

Aylesworth, L. 2014. Hippocampus kuda. The IUCN Red List of Threatened Species 2014:e.T10075A16664386. http://dx.doi.org/10.2305/IUCN.UK.20143.RLTS. T10075A16664386.en. https://www.iucnredlist.org.

Balasubramanian, R. and Murugan, A. 2017. Length-weight relationship of great seahorse, Hippocampus kelloggi (Jordan and Snyder, 1902), inhabiting Coromandel Coast, south-east coast of India. Indian J. Mar. Sci., 45: 1193-1197.

Bijukumar, A., Abraham, K. M. and Soumya, D. 2008. Morphometry and meristics of longnose seahorse, Hippocampus trimaculatus (Actinopterygii: Syngnathidae), from Kerala, south-west coast of India. Acta. Ichthyol. Piscat., 38(2): 149-155.

Basusta, A., Ozer, E. I., Girgin, H., Serdar, O. and Basusta, N. 2014. Length-weight relationship and condition factor of Hippocampus hippocampus and Hippocampus guttulatus inhabiting eastern Black Sea. Pak. J. Zool., 46: 447-450.

CITES 2018. Convention on international trade in endangered species of fauna and flora. Appendices I, II and III, valid from 1 July 2008. Geneva, Switzerland. http://www.cites.org.

Choo, C. K. and Liew, H. C. 2004. A record of seven seahorse species in East Malaysia, with notes on their conservation. Malay. Nat. J., 56: 409-420.

Choo, C. K. and Liew, H. C. 2006. Morphological development and allometric growth patterns in the juvenile seahorse Hippocampus kuda Bleeker. J. Fish Biol., 69(2): 426-445. https://doi.org/10.1111/j.1095-8649.2006.01105.x.

Gurkan, S. and Taskavak, E. 2007. Length-weight relationships for syngnathid fishes of the Aegean Sea, Turkey. Belg. J. Zool., 137: 219-222.

Ginsburg, I. 1937. Review of the seahorses (Hippocampus) found on the coasts of the American continents and of Europe. Proc. U.S. Natl. Mus., 83: 497-594.

Hale, M. E. 1996. Functional morphology of ventral tail bending and prehensile abilities of the seahorse, Hippocampus kuda. J. Morphol., 227(1): 51-65. doi.org/10.1002/(SICI)10974687(199601)227:1<51::AID-JMOR4>3.0.CO;2-S.

Harris, M. P., Newell, M., Daunt, F., Speakman, J. R. and Wanless, S. 2007. Snake pipefish Entelurus aequoreus are poor food for seabirds. Int. J. Avian Sci., 150: 413-15. doi. org/10.1111/j.1474-919X.2007.00780.x.

Kara, A. and Bayhan, B. 2008. Length-weight and length-length relationships of the bogue, Boops boops (Linneaus, 1758) in Izmir Bay (Aegean Sea of Turkey). Belg. J. Zool., 138: 154-157.

Kuiter, R. H. 2009. Seahorses and their relatives. Aquatic photographics, Seaford, Victoria, Australia, 334 pp.

LeCren, E. D. 1951. The length-weight relationship and seasonal cycle in gonad weight and condition in the perch (Perca fluviatilis). J. Anim. Ecol., 20(2): 201-219. https://doi.org/ 10.2307/1540.

Lourie, S. 2003. Measuring seahorses. (Report No. 4). version 1.0. Project Seahorse, Fisheries Centre, University of British Columbia, 15 pp.

Lourie, S. A., Pollam, R. A. and Foster, S. J. 2016. A global revision of the Seahorses Hippocampus Rafinesque 1810 (Actinopterygii: Syngnathiformes): Taxonomy and biogeography with recommendations for further research. Zootaxa, 4146: 1-66. https://doi.org/10.11646/ zootaxa.4146.1.1.

Lourie, S. A., Vincent, A. C. J. and Hall, H. J. 1999. Seahorses: an identification guide to the world's species and their conservation. Project seahorse, London, UK, $214 \mathrm{pp}$.

Lourie, S. A., Foster, S. J., Cooper, E. W. T. and Vincent, A. C. J. 2004. A guide to the identification of seahorses. Project Seahorse and TRAFFIC North America, University of British Columbia and World Wildlife Fund, Canada, $120 \mathrm{pp}$.

Moutopoulos, D. K. and Stergiou, K. I. 2002. Length-weight and length-length relationships of fish species from the Aegean Sea (Greece). J Appl. Ichthyol., 18(3): 202-203. https:// doi.org/10.1046/j.1439-0426.2002.00281.x.

Pauly, D. 1993. Fishbyte Section. Editorial, Naga, ICLARM Quart., 16, 26.

Petrakis, G. and Stergiou, K. I. 1995. Weight-length relationships for 33 fish species in Greek waters. Fish. Res., 21(3-4): 465-469. https://doi.org/10.1016/0165-7836(94)00294-7.

Siegel, S. 1956. Non-parametric statistics for the behavioural science. McGraw-Hill, New York, USA.

Sreepada, R. A., Desai, U. M. and Naik, S. 2002. The plight of Indian seahorses: need for conservation and management. Curr. Sci., 82(4): 377-378.

Teske, P. R., Hamilton, H., Palsboll, P. J., Choo, C. K., Gabr, H., Lourie, S. A., Santos, M., Sreepada, A., Cherry, M. and Matthee, C. A. 2005. Molecular evidence for long-distance colonization in an Indo-Pacific seahorse lineage. Mar. Ecol. Prog. Ser., 286: 249-260. https://doi.org/10.3354/ meps286249.

Thangaraj, M. and Lipton, A. P. 2011. Morphological characterisation of four selected seahorse species (Genus: Hippocampus) from India. Ann. Biol. Res., 2: 159-167.

Thomson, M. 1993. The locomotory and myotomal musculature of the seahorse, Hippocampus abdominalis. Ph. D. Thesis, University of Canterbury, New Zealand.

Vaitheeswaran, T. and Venkataramani, V. K. 2012. Lengthweight relationship of Hippocampus kuda (Bleeker, 1852) (Family: Syngnathidae) off Thoothukudi waters, south-east coast of India. Tamil Nadu J. Vet. Anim. Sci., 8: 119-125.

Vieira, R. P., Monteiro, P., Ribeiro, J., Bentes, L., Oliveira, F., Erzini, K. and Goncalves, J. M. 2014. Length-weight relationships of six syngnathid species from Ria Formosa, 
SW Iberian coast. Cah. Biol. Mar., 55: 9-12. http://hdl. handle.net/10400.1/8805.
Vincent, A. C. J. 1996. The international trade in seahorse. TRAFFIC Int., Cambridge, 172 pp.

Date of Receipt : $\quad$ 05.02.2019

Date of Acceptance : 16.06 .2019 